\title{
La colección Bicentenario
}

Jhon Henry Orozco Tabares

Colección Bicentenario (2010), Educación en la Independencia. Bogotá: Ministerio de Educación Nacional.

Por lo general se reseña un libro, esta vez resulta necesario hacer un rodeo mínimo, más o menos general, antes de llegar al texto que focaliza el ánimo y la señal. La Colección Bicentenario tiene forma de maleta y al abrirla emerge un conjunto plural de objetos, la mayoría de diversos formatos que comunican, a su modo, un tema o mejor un juego, un haz de relaciones finitas entre el Bicentenario como celebración y sus posibilidades en tanto acontecimiento histórico útil para el aprendizaje.

Es evidente también un espíritu investigativo que atraviesa lo materializado por la colección, desde el papel de las preguntas hasta el uso "didáctico" de las fuentes primarias y secundarias, pasando por la amplitud de relaciones con la historia, la ciencia, la narrativa, la economía, el arte, la geografía, la política, la religión, la fotografía, la sociología y la educación, la maleta despliega toda su escena.

Una conceptualización del mapa, del video, del afiche, de la imagen no excluye la necesidad de enumerar el contenido escrito de la colección, mucho más cuando se sabe que el esfuerzo editor va dirigido a las instituciones educativas del país y no hacia su circulación entre particulares. Integran los textos escritos de la maleta: (a) educación en la independencia, (b) castas, mujeres y sociedad en la independencia, (c) juntas e independencias en el Nuevo Reino de Granada, (d) geografía en la independencia, (e) economía en la independencia, (f) viajeros en la independencia, (g) poemas, fábulas e historias de la independencia, (h) la independencia en el arte y el arte en la independencia, (i) El Alférez Real de Eustaquio Palacio, (j) ciencia y Expedición Botánica en la independencia, ( $\mathrm{k}$ ) construcción de la patria nuestra: la Nueva Granada después de 1810, y (1) religiosidades y fiestas en la independencia. En resumen, habría que indicar una generosidad de relaciones por explorar. 
Dentro de esta amplia proliferación temática vale la pena detenerse en el libro que la colección dedica a la Educación en la Independencia, su estructura es claramente compilatoria: diez fotografías seleccionadas con cuidado presentan cinco capítulos de textos signados por el fragmento. Si bien el fragmento fue una de las estructuras preferidas por los filósofos del romanticismo alemán, en especial los hermanos Schlegel, su función es muy distinta en esta obra, constituye una muestra que es abordable de modo individual y no en su conjunto, a pesar de la unidad que supone mencionar sus acápites.

En total son 28 fuentes primarias, de las cuales siete corresponden a documentos firmados por Virreyes (Manuel Guirior, Antonio Caballero y Góngora (4), José Ezpeleta y Pedro Mendinueta), siete proceden de próceres de la independencia (Simón Bolívar (3), Francisco de Paula Santander, Francisco José de Caldas (2) y Camilo Torres) y el resto concuerdan con expedientes sobre planes de escuela, Reales Cédulas, informes y balances de época en materia educativa.

Contiene también una selección de trabajos investigativos más contemporáneos, que en palabras de los prologuistas "constituyen una significativa muestra del saber histórico que se ha construido sobre la educación en el país”, los señalo en orden de aparición: Jaime Jaramillo Uribe, Olga Lucía Zuluaga, John Lane Young, Alberto Martínez Boom, Armando Martínez Garnica, Jorge Conde Calderón, Luís Carlos Meneses y Luís Horacio López. Es evidente la diversidad de enfoques y modos de proceder en el análisis histórico que esta lista de investigadores encarna, pero no podría cerrar esta somera descripción sin mencionar los nombres de Germán Colmenares, y de modo muy especial, Guillermo Hernández de Alba, cuyos documentos para la historia de la educación en Colombia fueron utilizados en más de quince oportunidades por los editores, su nominación secundaria no oculta el valor de su legado. 